Final version:

Beverland, M.B., Lindgreen, A., and Vink, M. W. (2008), "Projecting authenticity through advertising: consumer judgment of advertisers' claims", Journal of Advertising, Vol. 37, No. 1, pp. 5-15. (ISSN 0091-3367)

For full article, please contact LindgreenA@ cardiff.ac.uk

\title{
Projecting authenticity through advertising: Consumer judgments of advertisers' claims
}

Michael B. Beverland, Professor of Marketing, School of Economics, Finance and Marketing, RMIT University, GPO Box 2476V, Melbourne, Victoria 3001, Australia. Email: mbeverland@yahoo.com. Telephone: + 61 (0) 416102492. Fax: + 61 (0) 399255986.

Adam Lindgreen, Professor of Marketing, Hull University Business School, Hull University, Hull, HU6 7RX, United Kingdom. Email: a.lindgreen@ hull.ac.uk. Telephone: + 31652437 933.

Michiel W. Vink, Market researcher, Tongelresestraat 6 G, 5611 VK Eindhoven, the Netherlands. Email: m.w.vink@xs4all.nl. Telephone: + 31 (0) 6239 10793. Fax: 31 (0) 40 2468054.

\section{Author bios}

Michael B. Beverland (Ph.D., University of South Australia) is Professor of Marketing in the School of Economics, Finance and Marketing, RMIT University, Melbourne, Australia. mbeverland@yahoo.com.

Adam Lindgreen (Ph.D., Cranfield University) is Professor of Marketing, Department of Marketing and Business Strategy, Hull University Business School, Hull, United Kingdom a.lindgreen@hull.ac.uk.

Michiel W. Vink (M.Sc., Eindhoven University of Technology) is Market researcher, m.w.vink@xs4all.nl.

\section{Acknowledgments}

Thanks to the Faculty of Technology Management at Eindhoven University of Technology for providing generous funding for this research. Thanks to Julie Napoli for feedback on an earlier draft. Thanks also to Daniëlle Smolders for providing some translation assistance. We also thank the editor and three anonymous reviewers for their constructive feedback on earlier drafts.

\section{Abstract}

Authenticity is a cornerstone of contemporary marketing. Yet, how do firms develop brand positions based on authenticity when marketing, and in particular advertising, is believed to 
be antithetical to such positioning? We examine how consumers assess the claims of Trappist and Abbey beer brands. We identify three forms of authenticity: pure (literal) authenticity, approximate authenticity, and moral authenticity. In each case, consumers draw on either indexical or iconic cues to form judgments of authenticity, although the type of cue and degree of abstraction differ across the three types. We also find that the informants are duped by careful advertisements, and explain this by proposing that the relationships between indexical and iconic cues are closer than previously thought.

\section{Key words}

Authenticity; tradition; brand advertising; interpretive research

\section{Introduction}

The use of the term "authenticity" in brand-related advertising has taken on new meaning in recent times. Originally used to reassure consumers of the genuine article (Beverland 2005b), modern uses of the term go beyond such claims, seeking to imbue the product with a set of values that differentiate it from other, more commercialized brands (Beverland 2005a; Rose and Wood 2005). For example, a spokesperson from the advertising agency that manages the Hauschka skincare brand states:

"The brand reeks of authenticity. The fact that it's not advertised everywhere and whispers rather than shouts its benefits, helps [it] convey something meaningful and subtle to consumers" (Goldstein 2003, p. 62).

Recent (2004-2005) billboard advertising for Wrangler jeans in Australia projects two slightly unkempt denim clad models under the tagline "Born Authentic." Visitors to the Wrangler website can read of the brand's history, sign up for 100-year celebratory brand events, and learn more about the brand. Likewise, fine wine producers seek to downplay scientific and commercial capabilities in favor of tradition, culture, and craft to create a powerful image of authenticity (Beverland 2005a; Beverland and Luxton 2005). Finally, one of Australia's largest brewers - Carlton United, recently won plaudits and achieved viral marketing success with their televised "Big Ad" campaign that deliberately poked fun at large advertising budgets and superficial storylines in an attempt to communicate authenticity by ironically critiquing the profession. Such strategies reflect a desire to situate the brand within the cultural landscape to ensure iconic status (Holt 2004). Claims of authenticity resonate with consumers (Beverland 2006; Fine 2003; Grayson and Martinec 2004; Kates 2004; Rose and Wood 2005), leading some authors to state "the search for authenticity is one of the cornerstones of contemporary marketing" (Brown, Kozinets, and Sherry 2003, p. 21).

However, using advertising to project an image of authenticity is difficult because methods of mass marketing are believed to undermine such claims (Beverland and Luxton 2005). For example, in his study of self-taught art, Fine (2003) identified how the use of mainstream advertising, segmentation techniques and direct selling reduced the authenticity and value of artworks produced by the Reverend Howard Finster. In the brand arena, managers of the Dunlop Volley shoe resisted exploiting (through mass advertising) the status of this once much-derided shoe among teens due to concerns about a potential loss of authenticity. Such a decision is believed to have been central in the successful re-birth of this iconic Australian brand (Beverland and Ewing 2005). Others have pointed out how firms that seemingly reject a customer orientation and its attendant marketing practices (including advertising) have 
created a strong point of differentiation in an age of undifferentiated "me too" products and offers (Beverland 2005b).

Given that claims of authenticity are often stylized and created by marketers (Arnould and Price 2000; Beverland 2006; Grayson and Martinec 2004; Rose and Wood 2005), a key question that arises is how advertising can successfully create or reinforce such claims (research has identified that advertising in the "right way" can reinforce claims of authenticity; Beverland 2006). We examine this question through interpretive interviews with beer consumers in Belgium and the Netherlands. Such a question is critical because although firms are increasingly turning to brand histories and historical associations as sources of market value (Grayson and Martinec 2004; Peňaloza 2000) and "a cultural marker of legitimacy and authenticity" (Brown, Kozinets, and Sherry 2003, p. 19), little is known about how firms create and maintain images of authenticity through advertising (Fine 2003; Grayson and Martinec 2004). For example, Peňaloza states, authenticity "is still not well understood in its market manifestations" (2000, p. 103). Although research has examined how consumers attribute authenticity to recreated historic sites and reality television shows (Grayson and Martinec 2004; Rose and Wood 2005), to our knowledge no examination of how consumers interpret advertisements to form judgments of (in)authenticity has occurred. Importantly, in the context of advertising the role and boundary conditions of both indexical and iconic cues in judgments of authenticity has not been addressed.

Therefore, this article addresses three questions. First, what are the different types of authenticity that consumers identify when they read advertisements? Second, what elements of advertising are integral to communicating these types of authenticity? Third, are consumers able to tell real from fake, given that research suggests consumers may effectively suspend disbelief when assessing marketers' claims of authenticity (Grayson and Martinec 2004), and authentic brand images may be created without regard for historical accuracy (Kates and Goh 2003)? This paper has the following structure. First, we present details of the research setting. Second, we present our method. Third, we present the findings, organized around the research questions. A discussion section addressing theoretical contributions, managerial implications, and limitations and future research follows.

\section{Research setting: Trappist brewing}

Trappist monks belong to the order of Cistercians of the Strict Observance. The Cistercians monasteries are divided into two great orders one of which was founded in 1662 by Armand de Rancé in the Normandy town of La Trappe. From this abbey the popular name "Trappist" originates. The monks from this order follow the $6^{\text {th }}$ century Rule of Saint Benedict, which declares monks should live by the work of their hands. To be self-sufficient the order of the Cistercians allowed the monks to sell production not needed for the abbey. When the abbeys of these monks were raised again after Belgian independence in 1830 they started to brew their own beer selling it under the label "Trappist beer" (Van den Steen 2003).

Trappist beer represents a fertile field for the study of creating and renewing sources of authenticity for two reasons. First, beverages "are highly symbolic and richly connotative product classes" (Mick and Buhl 1992, p. 320) and authenticity concerns issues of symbolism and meaning (Beverland 2005a). Second, the traditional beer category where Trappist beers compete is subject to debates and conflicts over authenticity - in particular critics, consumers and producers debate the authenticity of a true traditional or Trappist product. For example, as the Trappist breweries expanded their market beyond local confines into the international 
arena, a mass-produced alternative to Trappist beers emerged in the form of "Abbey beers" (an example is Leffe manufactured by Interbrew). During 1980-2000, the difference between Trappist beers and Abbey beers became less visible to consumers for several reasons: commercial breweries had licensed the name of an existing abbey, used names from abbeys that no longer existed, or simply invented a name such as Grimbergen, which is brewed by Alken-Maes. This allowed abbey beer brands to engage in advertising using images of monks to suggest a monastic origin (Van den Steen 2003).

To counter this competitive threat, in 1997 the appellation of origin "Trappist" was created by the International Trappist Organization. This logo, which states "Authentic Trappist Product," guarantees that the beer originates from a Trappist abbey, is produced by monks or secular collaborators controlled by Trappist monks, and that the majority of income is dedicated to social programs. In the beginning, only six abbeys could use the "Authentic Trappist Product" label. These were: Orval, Chimay, Rochefort, Westmalle, and Westvleteren in Belgium and La Trappe in the Netherlands. Achel (Belgium) was added in 1999, while La Trappe lost the right to the Trappist label because the brewery was sold to a commercial brewer.

\section{Research methods}

An interpretive approach was chosen for several reasons. First, there is a lack of research on the development of authenticity through advertising suggesting that a more exploratoryapproach is appropriate (Strauss and Corbin 1994). Second, the complexity of the authenticity construct (Rose and Wood 2005) and the conflicting research results on the attributes of authenticity suggest the need for qualitative research methods that probe consumers' responses to marketer claims of authenticity (Zaltman 2004). Third, since judgments of authenticity often reflect personal goals or the extended self (Arnould and Price 2000), we are working within a meaning-based tradition of advertising research (Mick and Buhl 1992), thus necessitating an interpretive approach.

Data were collected from three sources: consumers, marketers, and business buyers/industry associations (in total, we conducted 23 interviews). The focus of the findings will be on the interviews conducted with 12 consumers (two females and ten males aged between 20 and 54) of Trappist beers (interviews were also conducted at all six Trappist breweries, plus La Trappe to gain background information on their brand marketing programs. Further interviews were carried out with representatives from specialist distributors, retailers, a restaurant buyer, and an industry representative). In the consumer interviews we used semistructured depth-interviews (Mick and Buhl 1992) to explore consumer responses to a range of beer advertisements. Following questions about personal beer consumption, brand choice, and place of consumption, informants were asked to pick three images they associated with general perceptions of authenticity and inauthenticity from 45 images including pictures of production plants, historic buildings, new and old objects, and social situations (people together). These images allowed informants to explore notions of authenticity. This process also allowed us to understand each informant's response to marketer attempts at projecting authenticity (Zaltman, 2004). The same process was used in relation to discussions of authenticity and beer by drawing on 40 marketing images including advertisements (27 advertisements), bottle labels, and packaging from both Trappist and non-Trappist brewers. We used a mix of marketing materials because all seek to communicate messages about the brand. Following this, informants were presented with 24 different beers and asked to comment on each in terms of authenticity. These prompts enabled us to examine cues that 
signaled (in)authenticity and follow-up earlier lines of inquiry. All interviews were taped and then transcribed. This resulted in 203 A4 single-spaced pages (10-point font) of transcript.

Analysis of each interview was conducted prior to the next so the results could inform subsequent questioning, and help replicate the emerging themes across cases. Informant responses were analyzed through within-case and cross-case analysis by all three authors independently. During the cross-case analysis, theoretical categories emerged and were elaborated on during open and axial coding procedures (Strauss and Corbin 1998). To gain a further understanding of the way consumers interpreted advertisements and made judgments of authenticity, we tacked backed and forward between the transcripts and the relevant literature as a means of theory generation. Our interpretation was provided to two informants for member checking.

Throughout the study a number of methods for improving the quality of the research were adopted. First, data were triangulated from multiple primary and secondary sources. To do so, we collected data on the projection of authenticity from monks, marketers, business buyers and consumers, and drew from company literature and published sources on Belgian beer (e.g., Hieronymus [2005]). Second, three researchers provided independent interpretations of the findings. Third, the third author read widely about the industry, and two respondents were given the opportunity to provide feedback on initial findings. These three sets of activities all reinforced reliability and construct validity, and although colleagues performed independent coding of the transcripts, interviews were conducted by the same interviewers, reducing the role of bias (Lincoln and Guba 1985).

\section{Findings}

The informants identified three forms of authenticity: pure (literal) authenticity, approximate authenticity, and moral authenticity. Each informant primarily relied on one of the above forms to judge the authenticity of advertisements or brands. To do so, informants drew on different indexical and/or iconic cues in forming their judgments. A summary of these findings is presented in Table 1 .

Insert Table 1 here

\section{Consumer interpretations of authenticity}

\section{Pure (literal) authenticity}

Several of our informants defined authenticity in terms of unbroken commitments to tradition and place of origin (a continued connection to the place of founding). This definition drove Bram and Michael's reactions to the advertisements. For example:

"The little picture - the way it uses the butler, someone who serves the beer, pouring the beer on a tap, wearing traditional clothes, an apron, and using an old fashioned tap, it looks like he knows what he is doing. This picture with two men playing cards, old picture, name of the beer brand so yeah they want to associate with an old fashioned beer, an authentic beer, this could be an authentic picture - it's an old picture because of the old trolley." (Bram, reviewing two ads for Trappist beer) 
"Westmalle, there is no doubt, I've been there and tasted the beer and seen the fathers brewing the beer and all the pictures, and there was a man who could tell us about his predecessors and that to me is authentic, the bottle is important, the little neck, it seemed that it has never changed because it is far easier to produce glass with a straight neck I think and this means it dates from years that beer bottles were made by hand. The simplicity of the logos, the font resemble authenticity, a complex logo there is a problem they could not make them as complex not in many copies..." (Michael, reviewing a Trappist beer bottle)

Both Bram and Michael draw upon a range of cues that communicate absolute fealty to tradition in order to assess the authenticity of the brand. Both informants draw on historic cues to make a judgment that the product has remained completely unchanged from the original. Consistent with this definition of authenticity, cues that reinforce perceptions of authenticity are those that reinforce a continuance of historic practices including means of production, place of production, and product styling - attributes that form the essence of the Trappist product. To do so, informants drew on objective sources of information (Beverland 2005a; Postrel 2003) or indexical cues (cues that represent a factual or spatio-temporal link with something; Grayson and Martinec 2004, p. 298) in forming their assessments of (in)authenticity.

For example, advertisements must draw direct connections between these cues and the production of beer to be judged authentic, and effective. For example: "this one with the monks in a room represents authenticity but I can't associate them completely with beer because they're monks, now monks normally they make beer, but here they're just monks" (Bram, reviewing an ad for a Trappist beer). Direct links between indexical cues and the product or brand are essential because they provide a verifiable link between the product and past traditions including commitment to historic product styles, ingredients, production methods, and place of production. Without such a direct connection, the advertisement is less successful.

As well, small details or inconsistencies in advertisements may undermine claims of authenticity. For example:

"Here is a monk in a bar, but there is not much more to see, so neutral. Orval, could be a beer brand, it seems to be a ruin of the church, this is an old abbey church and Trappists are associated with the abbey but it is a bit away from the heart of the product, these language flags look like the modern computerized world - the confrontation with the ruin old tradition and the modern world, my feeling is it would be better without than with, you can choose the language and get a manual with it, authenticity to my mind with these beers is that it does not need much explanation, it just is." (Jimme, reviewing two Trappist beer ads and one Trappist label)

"This one stored in the cellar, traditional barrels, but there is modern lighting which should be avoided when used for marketing purposes.... The others don't look authentic because it looks quite modern because of the bright silver they use, it associates with the white of the beer but it doesn't look too authentic to me, maybe the picture of the abbey they could use more color in it because it looks a little bit abstract now, it's tokenism, they should use very natural colors, very warm colors-yellow brown. Orval, less authentic because of the picture not saying anything about beer it's just the sign of a fish coming out of the water and the letter type does not look old, it's not an old type, the label is triangular, no cross, so I don't associate it with a beer label.... it doesn't matter that it is a little label, the label as a whole 
does not say really authentic beer." (Bram, reviewing three ads from various brewers and one bottle of Trappist beer)

The two passages above represent discussions primarily about the advertisements and labeling for Orval, an actual Trappist beer. A number of small details undermine claims of authenticity because they dilute the perceptions of factual commitments to tradition. Jimme and Bram do not therefore judge the product in terms of its closeness to the "real thing" (or iconic authenticity; Grayson and Martinec 2004), but question the brand's legitimacy per se. For Jimme (who defined authenticity as "preservation of history"), the lack of a direct connection between the stylized picture of the abbey and the product (the stylization would usually suggest iconicity), and the presence of modern images (translations of product information into three languages and a web link) combine in such a way to dilute the product's claim of authenticity, and therefore undermines the desirability of the brand.

The presence of the three flags was also noticed by Bram who noted that not one was Belgian, which raises questions about the product's origin. Other small details such as the presence of modern lighting, font types, and colors in the advertisements undermined claims of authenticity because they diluted tradition. With the focus on objective verification, the simultaneous presence and absence of certain cues reinforced perceptions of (in)authenticity.

What explains this preference for indexical cues of authenticity, and in particular the provision of a perceptually consistent image? Bram, Kris, Jimme, and Michael all stated they consumed Trappist beers during a long stay within a pub or cafe in the company of dear friends or loved ones. For example, "If there is a farewell party, in the evening I see a friend, at a cafe I like to drink Trappist (La Trappe), it is more of an occasion beer" (Bram). Although the majority of their beer consumption (including that in pubs) was of branded mass-market ales or lagers (as opposed to heavier and darker Trappist styles), in cases where Trappist beers were desired these consumers were highly loyal to the product category. Therefore it was vital that consumers gained the genuine article. For example:

"The name makes, the brand name is calling up tradition, when you are with a couple of friends, the only thing people know is the name beer, I want a beer, when they think about Trappist, they want a traditional beer, Trappist is the tradition beer. When you order a Trappist you get the glass, you get the bottle, people want to know they get a Trappist, just having Triple, they would wonder what they have, they wanted a Trappist" (Kris).

Because many beers attempt to mimic Trappist brands through the use of religious imagery and words associated with Trappist styles (e.g., Triple), small perceptual-level details that were inconsistent with their view of a traditional beer (such as multi-language translations, the use of highly complex and abstract imagery without connections to beer, and modern colors, bottles and font styles) led to judgments of inauthenticity. Thus, this form of authenticity - absolute fealty to historic traditions - was critical to consumers seeking to make quick in situ judgments about the genuiness of a product class. As well, identifying a product as authentic helped consumers gain control over their consumption decisions (cf. Hochschild 1983). As such, providing a consistent product image using indexical cues at the perceptual level was essential for consumers seeking to verify the authenticity of the product they received. A re-reading of Beverland's (2006) study of authenticity in wine consumption identifies that indexical cues were given preference when consumers were judging the claims made by marketers at the winery in situations where consumers desired a local product, 
whereas more abstract iconic cues were used to form generalized perceptions of a product's authenticity and status.

Unlike the other informants, the consumers commented on so far did not place any generalized value upon authenticity - it was important at a situational level but was not valued as an end-in-itself nor a part of the extended self (i.e., the search for pure authenticity did not characterize generalized patterns of consumption). This section therefore confirms and bounds Grayson and Martinec's (2004) view that the process of attributing authenticity to an object is different from the process of self-authentication, contributing to our understanding of how consumers process cues to form judgments of authenticity.

In regards to the effectiveness of advertisements in communicating pure authenticity, Table 1 identifies that since consumers are seeking information to make a quick in situ judgment about the genuineness of the product on offer, advertisements must draw direct links between the brand and actual traditional practices, including monks actively producing beer with traditional equipment and selling beer in traditional garb. As well, the advertisement cannot be diluted with modern cues or touches and must appear to be a literal replication of the past through historically accurate colors, fonts, and type (advertisements should therefore be simple because complex imagery was not possible in the past). For ads to successfully communicate pure authenticity they must focus solely on brand attributes - "those descriptive features that characterize a product or service." (Keller 2003, p. 71)

\section{Approximate authenticity}

Informants also focused on symbolic or abstract impressions of tradition that were created by advertisements when making judgments of authenticity. In these cases, although authenticity was still defined in terms of tradition, absolute fealty to the past was unnecessary, and in some cases undesirable. For example:

"What is more important is the taste, the aura, the authenticity.... It's the combination with the religion that makes it special. A beer that has been made by the monks is special. That gives it the mystique.... The tradition is very important, very special..." (Karl)

Karl's definition is consistent with iconic authenticity whereby products or objects are authentic if they approximate historical referents (i.e., if they fit with consumers' mental picture of how things ought to be; Grayson and Martinec 2004). In contrast to the informants seeking indexical authenticity, Karl focuses on the overall abstract impression created by the ads - using terms such as "aura" and "mystique" instead of seeking perceptual cues that may give the product away as a fake. Other informants used similar standards when judging the advertisements. For example, Marlene defined authenticity as a feeling that a product has an origin "way back, I can't define that, but some feeling that the product has its origin way back." Marlene's definition contrasts with those of Jimme and Bram in terms of its precision (less), and focus on cues (emotional as opposed to rationally verifiable cues). For Marlene, the fact that the product conveys a sense of history rather than proves its historical connections is central to her definition of authenticity. This affects her interpretation of advertisements. For example:

"La Trappe, it is an old abbey, they are brewed in the past by fathers, they are not totally now, but that does not impact on the authenticity because it is always a trade-off between price and process, if you have an old process with monks, price can be higher but then they 
don't have to make money, it's difficult, but to me it does not affect my view of authenticity. What would affect it is the bottle, you have two beers of La Trappe, the logo of the Triple is more basic, simple logo, the white beer looks like a Hoegaarden copy-you know, put in the abbey, the silver-blue, the yellow, the white and you have a white beer, the Triple is more authentic. If you look at all white beers that are sold, they all use the white, silver, blue and yellow label - the white maybe authenticity is a bit of differentiation, on the other hand I don't know if they were brewed by Trappists in the past, but I have the feeling so it is authentic." (Marlene, reviewing three non-Trappist beers)

Marlene's passage reinforces her definition of authenticity as a "feeling." In contrast to Jimme and Bram, Marlene focuses on the overall emotional impression created by the various cues in the logos and advertisements in assessing claims of authenticity. Marlene applies a mental picture of what a Trappist beer ought to look like in assessing the status of a non-Trappist beer, La Trappe. Importantly, Marlene allows for change in her assessment of authenticity, identifying that although the beer is no longer brewed by the monks it is still authentic because it gives that impression through the combined effects of its logo, bottle shape, and product style. This point is reinforced through her discussion of the white beer-a popular style forbidden under Trappist rules. Although Marlene senses it is not as authentic as the Triple (a traditional high alcohol style of beer), she still assesses it relatively positively because it retains a sense of tradition and history. Importantly, Marlene suggests that the problem with the white beers is not the departure from tradition, but that they are all presented in the same way as the popular mass-market beer Hoegaarden.

In contrast to pure authenticity, informants seeking approximate authenticity were open to changes in the practices associated with the Trappist brands, as long as such changes did not undermine the brand's essence. For example, the use of language translations and web links on bottles were not problematic because such cues were necessary for business and did not dilute the substantive nature of the Trappist brand. Informants also focused on lived tradition — or a connection between the past and present, whereby historic traditions evolved to meet modern standards in order to ensure continuity. For example,

"The Orval picture with the old abbey in which they brewed the beers a lot of years ago, on the other hand you see the rebuilt tower, you see the brand has lived for a lot of years but it is still there, history is fine, but you should know it lives right now, which is why I love the building characteristics of the old tower and the new rebuilt past." [I: It lives?] "If I think of authenticity I should see a long tradition but the tradition should not be ended.... the old brewery, you see they have conserved it, especially to show the tradition on purpose, you see the company still lives, but you see they really lived because of their history and that is what they want to preserve." (Tim, reviewing an ad for a Trappist beer)

Tim's passage focuses on how the combination of historic and modern cues results in an overall impression of authenticity - in this case how a living monastery / brewery should look like (such a view is particularly important given the practice by mass-market breweries of simply buying the rights to use the names of defunct Orders). That is, the cues used are not necessarily factual links to time and place (as in indexical authenticity) nor is Tim going through a process of verification-instead Tim focuses on connections between his personal view of authenticity and the overall impression created through the blend of modern and historic cues. In this case, Tim describes the advertisements in more emotive terms, reflecting how he loves the fact that important traditions are conserved (another value-laden term), and he recognizes that this is being done deliberately. Informants like Tim therefore neither 
suspend disbelief in attributing authenticity to new things (Grayson and Martinec 2004) nor view Orval as a diluted version of the original (Postrel 2003). For example, although Tim happily plays along with the marketer from Orval, he does so in an informed way, and will only tolerate so much. For example:

"The Duchese [Ad] pretty much looks the same as other beers I picked as authentic, but you see the word 'Flemish art of brewing' and that to me is not authentic, because of the language, it is in English, if it is in Flemish you say it in Dutch, and if you target another market you translate everything, here they have English, Dutch and French, and the words 'Flemish art of brewing' is a bit too commercial. It's like a businessman in Holland with millions who wanted to produce a race car, and who found a family who once produced a car for the queen, and asked the family to use the name as well, to me there is no tradition, the history part of it is gone. With Duchese it's as if a businessman looked for an empty abbey to produce in and brand whereas instead there should be an abbey brewing beer for it to be authentic." (Tim, reviewing an ad for a non-Trappist beer)

Tim rejects the Duchese brand because he perceives that it is not sincere - it is effectively all style with no substance. In contrast, Orval is authentic because the advertisement neither hides the modern side of the business nor rejects tradition completely. Importantly the Orval ad suggests authenticity through imagery rather than explicit claims that do not seem right either historically or contemporaneously. Tim's discussion of the Duchese brand identifies his understanding that several large breweries have attempted to stage authenticity by buying the rights of old Abbeys or even invented Abbeys to give their beers an aura of authenticity. Tim sees through this attempt because the cues do not reinforce a sense of continued tradition.

In summary, judgments of approximate authenticity involved iconic cues. Importantly, and in contrast to pure authenticity, approximate authenticity involved abstract cues that combined to create a sincere impression. As well, informants openly recognized that such cues were used for commercial benefit but appreciated that producers retained important traditions and did not hide their contemporary practices - in fact the projection of a continued tradition reinforced perceptions of authenticity. Therefore, consumers had little problem attributing authenticity to new objects (cf. Grayson and Martinec 2004) as long as they were placed within a temporal setting. The fact that consumers recognized that seemingly real traditions were used for commercial effect (while contrived traditions were inauthentic) suggests that tensions between commercial motivations and authenticity may be overplayed, and strategies such as decoupling may be unnecessary or a waste of resources (cf. Beverland 2005a).

Also, judgments of approximate authenticity were representative of a more generalized consumption practice than for assessments of pure authenticity. For example, those seeking products that conveyed a sense of lived tradition purchased brands in order to reflect a deeper sense of self. In contrast, those seeking pure authenticity compartmentalized concerns of authenticity into specific consumption situations. For example, Marlene identified that authenticity was "the basis of the product" and highlighted that she went out of her way to purchase products that "had a real connection to time and place and real people." Marlene then opened up the discussion to identify a variety of food brands that fit this profile, including dairy products, clothing, and automotive. Authenticity judgments were applied in a general sense, across product categories, and resembled a self-referential act (Arnould and Price 2000) that allowed consumers to connect to time, place and cultural traditions that they believed to be important parts of their identity. Thus, attributing authenticity to things 
reflected a deeper search for self-authentication, in contrast to the view put forward by Grayson and Martinec (2004). These informants focused on authenticity as a value in itself (as opposed to situational use value).

In regards to the effectiveness of advertisements in communicating approximate authenticity, Table 1 identifies that since consumers are seeking information to ensure their product choice enables them to achieve self-authentication through connection to time and place

advertisements must create an emotional impression that the brand is from the past. This was achieved by more stylized abstract cues than for pure authenticity. Advertisements could use cues that suggested (rather than providing verifiable evidence) religious origins, connection to place, monks' involvement in production, and links to the past through traditional product identifiers, and simple presentation. Advertisements could also feature modern touches such as website addresses and language translations. Therefore (and in contrast to pure authenticity), for ads to successfully communicate approximate authenticity they must focus on brand benefits - "the personal value and meaning that consumers attach to the product or service attributes.” (Keller 2003, p. 71)

\section{Moral authenticity}

The final form of authenticity involved two forms of moral judgments. Informants attributed higher moral status to traditional craft processes per se. This judgment primarily involved iconic authenticity as informants valued an overall impression of small, handcrafted production, made by artisans as an end-in-itself. For example:

"They are working with their hands; they have been doing it for a long time, smelling the beer, packaging the beer with their hands... [The man smelling?] The fact he is smelling it by himself and it seems he as a person is influencing the process and that he adapts the process to his own likes and the way beer should be according to him and it is not some kind of computerized process and their is a human factor to it." (Johan, reviewing an ad for a nonTrappist beer)

"Authentic? When it is created out of some inner need, not focused on some external demand just because somebody believes in it, it's authentic — authentic behavior is behavior not focused on pleasing someone else but comes from something deep inside. For example, playing football you do not copy the style of another team, you do not buy others players, you develop your own style of play your own players. Chelsea is not authentic...." (Peter)

Johan and Peter's passages place the emphasis squarely on the motive, means and ends (production of high quality product) of the creative act, focusing on the importance of producers being engaged with production and motivated by a love of the task. As well, they emphasize the essential human component of the process rather than just history per se. The fact that both informants (and Joost - quoted next) discussed authenticity in comparative terms - "Craftsmanship, pure ingredients. I would add to the opposite of these things - mass consumption and production versus very limited production, these would be inauthentic"emphasizes the moral component of their judgment. For these informants the fact these brands are old or local is relative meaningless. Instead, authenticity comes from the sense that a passionate creator is involved in making products, and is motivated primarily by their love of craft, rather than the possibility of financial reward. Consistent with approximate authenticity, moral authenticity is a self-referential act in that it defines their preferred consumption choices, rather than just being situational. However, unlike approximate 
authenticity, judgments of moral authenticity involve perceptual level (albeit stylized) cues that seem to indicate passionate creative people involved in production, solitary enjoyment of the product, or the use of traditional equipment (see Peter's passage below) to gain an overall sense that the brand conforms to their sense of what an authentic craft product would be like (cf. Grayson and Martinec 2004). Thus, moral authenticity involves iconicity because consumers desired a sense or impression of the love of craft, as opposed to an impersonal mass-produced product. As well, the preferred advertisements were also interpreted from a comparative standpoint - that is these informants focused not just what was in the ad, but also on what was missing. For example:

"This picture of the monk drinking his beer is the most appealing, it is the first connection when I think of Trappist beer, the monk drinking and enjoying it. [The second picture] He is smelling and tasting one of the ingredients, maybe he is testing the quality of a good beer, he is very connected with the product, when you have mass production they don't taste it anymore, they just take a sample and test it in a lab, and he is smelling it - this man has a very long specialization in making beer, he has the right smell for it, it is hard to see it in the picture, and the picture is black and white so it looks a little old fashioned." (Peter, reviewing an ad for a non-Trappist beer)

In summary, moral authenticity is a self-referential act, but one different from approximate authenticity. Consumers seeking moral authenticity were less interested in history or connection to time and place, and instead were focused on choosing brands that were genuine in their intent - be it evidenced by real commitments to social programs or through the love of craft. In regards to the effectiveness of advertisements in communicating moral authenticity, Table 1 identifies that since consumers are seeking information to ensure their product choice reflects their personal moral values, advertisements must create a factual or emotional sense that the brand is committed to traditional moral practices. This was achieved by more stylized perceptual cues such as images of monks' involvement in production, cues associated with small-scale hand-crafted production methods, and cues that communicated a profound love of the product and the craft of producing it.

\section{Can consumers tell real from fake?}

Our final question focused on whether and how advertisers could effectively dupe consumers with inauthentic products. We did this by asking each informant to discuss 24 different beers (we provided them with the bottles) in terms of their authenticity. We included all the Trappist beers, plus several Abbey beers, and some global brands. All the informants were duped in some way when considered against an objective standard of authenticity (i.e., the real Trappist beers). For example, Karl's response below came from this process.

"Leffe, you see again an abbey, old fashioned letters, the darker colors again, that is it. It looks authentic to me, it's quite a well known brand, it is not possible to produce it without mass production, they are quite a big brewery, maybe it is not possible to brew all the beer in an old fashioned way, maybe they use packaging with an electronic line. Grimbergen beer, old fashioned colors, they use a lot of yellow and light brown in order to show it is beer, because beer is also this color, old fashioned letters, really an old brewery since 1128, or at least they started in an authentic way in order to keep that appearance they still brew it in that way, of course adjusted a little for the times we have now...." (Karl, reviewing several nonTrappist beer labels) 
Karl defined authenticity in terms of a sense of history and tradition - the fact the beer is part of living history, produced in working monasteries and retaining essential elements of tradition. Yet, despite recognizing he is dealing with mass-market brands, Karl authenticates two brands (Leffe and Grimbergen) that represent probably the least authentic traditional beer brands we could find. For example, Grimbergen's supposed connection to time and place is pure fantasy. The dating of 1128 is a marketing invention and the beer is brewed in the parent company's factories throughout Belgium. Leffe has a similar story. Why did Karl (and Tim and Marlene) authenticate such products that are objectively not authentic Trappist beers? First, these two beers conform to each informant's mental picture of how a traditional beer should look, even though they provide no real connection to time and place (thus, these informants are duped as they have not actually achieved self-authentication). Second, the marketers of these beers have successfully positioned their products as Trappist-styled products through subtle marketing and use of imagery, color cues, and font styles to suggest authenticity. Whereas overt religious iconography and pictures of smiling monks are easily spotted as fakes, more subtle products (that could easily be developed through careful market testing) are judged as authentic, and thus included within the consideration set. Informants looking for "hand-crafted" products (such as Peter and Johan) also struggled to make accurate distinctions, often attributing authenticity to brands with very stylized pictures of "jolly monks" tasting or drinking beer (since Trappist Orders do not want to promote alcohol consumption or impinge on monastic life they forbid the use of joyous images or pictures of monks in marketing communications).

Other informants struggled to tell real from fake. For example, Hans, an informant that sought pure authenticity, was able to see through obvious attempts to suggest authenticity but nevertheless had real difficulty in selecting real Trappist brands that did not fit his rigid definition of authenticity.

"What is striking if you look at Leffe and so on they are trying to suggest they are Trappist beers by placing a monk on it and they show temples of the Duke, castles, the sign of the abbey, Leffe the drawing of the abbey, St Bernardus the monk, the true authentic ones they do not have anything like that. They just say Westmalle, Orval, Rochefort Trappist number 8 and number 6 and 10, you know it, people who buy these beers, many know who are the true Trappists and they do not have to claim it anymore. I do not like this one from Rochefort because it seems like it has been created to look old and if it has been created to look old it is not authentic, timeless font and I don't like that... for the same reason I'm in doubt about Rochefort, it could be only suggesting it is old." (Hans, reviewing several Trappist and nonTrappist beer labels)

Hans correctly identifies that mass-produced brands such as Leffe are deliberately seeking to draw on cues that suggest authenticity, and in particular suggest they are Trappist brands. Nevertheless, Hans' reliance on perceptual cues alone means he struggles to attribute authenticity to the Trappist brand Rochefort. This group of informants had difficulties judging the Orval brand for the same reason. In both cases, these brands did not use overt links between beer production and monastic life on their bottles (Rochefort uses a very stark white label with their name on it and Orval uses a slimmer bottle with a fish logo on it). This reliance on abstract cues (which have been used for many years), overt claims of authenticity (the Trappist logo), and the use of modern touches such as website links worked against these brands when consumers sought to make snap in situ judgments about authenticity. 
Each informant made judgments of authenticity according to indexical or iconic standards. That is, some preferred substantive cues that helped verify claims of authenticity while others preferred symbolic cues that ensured the right impression. However, the examples identify that the majority of informants reject outright claims of authenticity (due to cynicism about marketer claims) but also fail in many instances to choose the right product - be it a Trappist beer in a specific social setting, or a brand that reinforces a sense of self. Since the informants desired "the real thing" how are we to explain the fact that all were regularly duped? We propose that the distinction between indexical and iconic cues has been overplayed. In each case, informants are making positive judgments about authenticity based on normative views regarding authenticity. That is, indexicality is being achieved via iconicity. We support this case with one further insight. All the informants that had visited specific Trappist monasteries such as Westmalle correctly identified this as an authentic Trappist beer (despite the label being little different to Rochefort). Providing this real connection between product and monastic life ensured a substantive point of difference for the Westmalle brand (in contrast, few abbey beers have real monasteries behind them that one can visit). In this case, consumers are experiencing an objective indexical connection to the brand's story that both reinforces their idealized view of authenticity and overrides cues that may raise questions in the consumer's mind. Outside of these examples, all informants are selectively seeking out specific and often stylized cues to verify the authenticity of the product. Such cues are iconic but are given indexical status by the informants.

\section{Discussion}

The findings contribute in a number of ways. First, we identify that advertising does have a role to play in reinforcing images of authenticity. To date, researchers have questioned whether such a commercial medium as advertising can enhance claims of authenticity. We find that advertisements can effectively communicate three forms of authenticity. As research on authenticity has often concerned how producers seek to communicate authenticity (Beverland 2005a) or how tourists attribute authenticity to historic sites (Grayson and Martinec 2004), the focus on how consumers attribute authenticity to advertising and brands is a contribution is its own right. Furthermore, we identify that previous forms of authenticity_indexical and iconic — can be transferred from historic sites to marketing communications. Such a finding goes beyond the extant research on attributing authenticity to brands (Beverland 2006) by identifying a relationship between consumer motives and responses to single and multiple advertising cues. As well, we identify the role both indexical and iconic cues play in particular judgments of (in)authenticity, a point not explained by previous research.

Our second contribution relates to this transfer-we provide boundary conditions for indexical and iconic cues of authenticity, and suggest a relationship between them. In addressing our three research questions, we suggest that consumers rely primarily on indexical cues when they are seeking control- either over specific purchase occasions or in general cases such as ethically minded consumers. Yet, the execution of advertisements to each consumer is very different - an issue we address in managerial implications. Grayson and Martinec (2004) suggest that processes of self-authentication and attributing authenticity to things are two different things. Our findings suggest a boundary condition to this view. When consumers are making snap judgments regarding the genuineness of a product then the processes are quite separate. In cases where consumers are engaging in self-referential behaviors or consumption is part of the extended self we propose that the two processes are similar. Future research is necessary to bare this contention out. 
Furthermore, we suggest a more provocative finding in relation to indexical and iconic cues - that the two are interrelated. In addressing the three research questions we identify that informants struggle to identify authentic from fake. In each case, the informants apply their standards of authenticity to advertisements yet still make incorrect decisions (in objective and personally relevant terms). Research to date has examined whether consumers use either indexical or iconic cues to form judgments of authenticity (Grayson and Martinec 2004). This research suggests that consumers can attribute authenticity to fictional sites (Sherlock Holmes' residence) - a finding that troubled Grayson and Martinec. These authors wondered whether consumers effectively suspended disbelief in such circumstances. However, we offer an alternative view. We suggest that indexicality is reached via iconicity - that is consumers apply normative standards to form what for them are objective judgments of authenticity.

\section{Managerial implications}

The findings also have implications for managers. The paper opened with a number of examples of brands deliberately seeking to position themselves around authenticity. The findings demonstrate that advertising has a very important role to play in reinforcing claims of authenticity, although overt statements (such as the Wrangler "Born Authentic" example, or the "Authentic Trappist Product" logo) may undermine such claims with all but a few consumers. Therefore, advertisers should focus on suggesting authenticity indirectly using the cues identified in Table 1. However, creatives and brand marketers should firstly identify how their target consumer segment(s) define authenticity, and even pre-test copy with different segments to ensure the brand message in not undermined by poor execution (including the inclusion or omission of small details) since we find that carefully crafted ads can suggest authenticity to even the most skeptical consumers.

The findings also have implications for bearers of tradition or traditional holders of cultural capital. First, overt appellation of origin programs may only have limited effect in the marketplace. Second, behind the scenes tours not only allow consumers to experience the authenticity of the firm's story (Cohen 1988; MacCannell 1973); they also may create or confirm consumers' perceptions of what authenticity is. Our findings demonstrate that in instances where consumers had experienced the story behind the brand first hand, these brands formed part of their consideration set, regardless of whether advertising cues that normally indicated inauthenticity were present. Since many holders of tradition can substantively back up their claims of authenticity, and many mass-market firms cannot justify the expense of such activities or carry it out effectively (Beverland 2005a), we suggest these firms use such experiential strategies to enhance their brand and defend themselves from symbolic attacks.

\section{Limitations and future research}

The findings have a number of limitations. First, the exploratory results need further empirical examination to ensure their transferability and comprehensiveness. Second, the findings also need empirical examination in other product and brand contexts including realms where issues of authenticity are not so overly apparent such as business-to-business advertising where indexical cues may be very important given the dangers of using "fake" ingredients or parts. Third, future research is also needed in different cultural contexts and with novice consumers to identify whether these findings are generalizable across ethnicity and product involvement. There are also further avenues for future research. The informants 
were often duped by credible claims of authenticity. Yet, when is an advertisement credible or not? The informants suggest a threshold effect - that an advertisement that doesn't "scream too loudly" is more likely to be judged authentic. Experimental scenarios may be needed to tease out these effects. As the findings identify that self-authentication is critical to some consumers' definition of authenticity, future research is needed on why consumers respond to certain images of authenticity and not others. We suggest that an important moderating variable will be consumer goals or life projects (Arnould and Price 2000; Fournier 1998). Finally, future research should also examine the potential interrelationship between indexical and iconic cues perhaps using life story interviews (Mick and Buhl 1993) to identify whether consumers idealized construction of authenticity eventually takes on an objective status.

\section{References}

Arnould, Eric J. and Linda L. Price (2000) “Authenticating Acts and Authoritative Performances: Questing for Self and Community," in The Why of Consumption: Contemporary Perspectives on Consumer Motives, Goals, and Desires, S. Ratneshwar, David Glen Mick and Cynthia Huffman, eds., London: Routledge, 140-163.

Beverland, Michael B. (2005a), "Crafting Brand Authenticity: The Case of Luxury Wine," Journal of Management Studies, 42 (July), 1003-1030.

------. (2005b), "Brand Management and the Challenge of Authenticity," Journal of Product and Brand Management, 14 (7), 460-461.

-----. (2006), “The 'Real Thing': Branding Authenticity in the Luxury Wine Trade," Journal of Business Research, 59 (February), 251-258.

Beverland, Michael B. and Michael T. Ewing (2005), "Slowing the Adoption and Diffusion Process to Enhance Brand Repositioning: The Consumer Driven Repositioning of Dunlop Volley," Business Horizons, 48 (October), 385-392.

Beverland, Michael B. and Sandra Luxton (2005), "Managing Integrated Marketing Communications (IMC) through Strategic Decoupling," Journal of Advertising, 34 (Winter), 103-116.

Brown, Stephen, Robert V. Kozinets, and John F. Sherry Jr. (2003), "Teaching Old Brands New Tricks: Retro Branding and the Revival of Brand Meaning," Journal of Marketing, 67 (July), 19-33.

Cohen, Erik (1988), “Authenticity and Commoditization in Tourism," Annals of Tourism Research, 15, 371-386.

Fine, Garry A. (2003), "Crafting Authenticity: The Validation of Identity in Self-Taught Art," Theory and Society, 32 (April), 153-180.

Fournier, Susan (1998), "Consumers and Their Brands: Developing Relationship Theory in Consumer Research,” Journal of Consumer Research, 24 (March), 343-373. 
Goldstein, Nikki (2003), "What's Up Doc?” The Australian Financial Review Magazine, Summer, 62.

Grayson, Kent and Radan Martinec (2004), "Consumer Perceptions of Iconicity and Indexicality and Their Influence on Assessments of Authentic Market Offerings," Journal of Consumer Research, 31 (September), 296-312.

Hieronymus, Stan (2005), Brew Like a Monk: Culture and Craftsmanship in the Belgian Tradition. Boulder, CO: Brewers Publications.

Holt, Douglas B. (2004), How Brands Become Icons, Cambridge, MA: Harvard Business School Press.

Hochschild, Arlie R. (1983), The Managed Heart: Commercialization of Human Feeling, University of California Press, Berkeley.

Kates, Steven M. (2004), "The Dynamics of Brand Legitimacy: An Interpretive Study in the Gay Men's Community,” Journal of Consumer Research, 31 (September), 455-464.

Kates, Steven M., and Charlene Goh (2003), "Brand Morphing: Implications for Advertising Theory and Practice," Journal of Advertising, 32 (Spring), 59-68.

Keller, Kevin-Lane (2003), Strategic Brand Management, Sydney: Prentice-Hall.

Lincoln, Yvonnah S., and Egon Guba (1985), Naturalistic Inquiry, $1^{\text {st }}$ ed., Beverly Hills, CA: Sage Publications.

MacCannell, Dean (1973), "Staged Authenticity: Arrangements of Social Space in Tourist Settings," American Journal of Sociology, 79 (3), 589-603.

Mick, David Glenn and Claus Buhl (1992), "A Meaning-Based Model of Advertising Experiences," Journal of Advertising, 19 (Dec), 317-338.

Peňaloza, Lisa (2000), “The Commodification of the American West: Marketers' Production of Cultural Meanings at the Trade Show," Journal of Marketing, 64 (April), 82-109.

Postrel, Virginia (2003), The Substance of Style: How the Rise of Aesthetic Value is Remaking Commerce, Culture, \& Consciousness, $1^{\text {st }}$ ed., New York, NY:

HarperCollinsPublishers.

Rose, Randal L. and Stacey L. Wood (2005), "Paradox and the Consumption of Authenticity through Reality Television," Journal of Consumer Research, 32 (September), 284-296.

Strauss Anselm and Juliet Corbin (1998), Basics of Qualitative Research, $2^{\text {nd }}$ ed., Newbury Park, CT: Sage Publications.

Van den Steen, Jef (2003), Trappist: Het Bier en de Monniken, $1^{\text {st }}$ ed., Leuven: Allmedia.

Zaltman, Gerald (2004), How Customers Think, Cambridge, MA: Harvard Business School Press. 